\title{
Glycosyl Exchange of Unactivated Glycosidic Bonds: Suppressing or Embracing Side Reactivity in Catalytic Glycosylations
}

\author{
Joshua L. Martin," Girish C. Sati," Tanmay Malakar", Jessica Hatt, Paul M. Zimmerman, ${ }^{*}$ and John Montgomery* \\ Department of Chemistry, University of Michigan, Ann Arbor, MI 48109-1055, USA \\ \# equal contributors to this work
}

\begin{abstract}
While developing boron-catalyzed glycosylations using glycosyl fluoride donors and trialkylsilyl ether acceptors, competing pathways involving productive glycosylation or glycosyl exchange were observed.

Experimental and computational mechanistic studies suggest a novel mode of reactivity where a dioxolenium ion is a key intermediate that promotes both pathways through addition to either a silyl ether or to the acetal of an existing glycosidic linkage. Modifications in catalyst structure enable either pathway to be favored, and with this understanding, improved multicomponent iterative couplings and glycosyl exchange processes were demonstrated.
\end{abstract}

Introduction

Carbohydrates are crucial to a broad array of biological processes relevant to human health and wellbeing. ${ }^{[1]}$ Research in this area is complicated by the broad diversity of possible structures ${ }^{[2]}$ and the heterogeneity of carbohydrates in biological systems. ${ }^{[3]}$ This understanding of the crucial role of carbohydrate building blocks has led to a surge in demand for enabling tools, answered by significant advances in mass spectrometry of complex mixtures ${ }^{[4]}$ and labeling approaches to image or detect carbohydrates expressed on cell surfaces. ${ }^{[5]}$ Various perspectives ${ }^{[6]}$ and funding agencies ${ }^{[7]}$ have recognized that the synthesis of complex carbohydrates is a limiting step for advancement in the glycosciences due to difficulties in controlling regio-[8] and diastereoselectivity ${ }^{[9]}$ as well as challenges in preparing the appropriately protected building blocks. ${ }^{[10]}$

A recent focus of our lab is the development of efficient catalytic methods for glycosylation, using the combination of glycosyl fluorides as the glycosyl donor and silyl ethers as the glycosyl acceptor. ${ }^{[11]}$ Glycosyl fluorides are an important class of glycosyl donors ${ }^{[12]}$ for which a wide variety of acid activators have been 
reported, including conditions developed by Mukayama ${ }^{[13]}$ and Nicolaou. ${ }^{[14]}$ These approaches to glycosidic bond formation have provided optimal reactivity in several challenging syntheses, including a recent, notable report that employed glycosyl fluorides to carry out a $[31+30+30+30+30]$ glycosylation en route to a 151-mer

polysaccharide. ${ }^{[15]}$ Silyl ethers have rarely been employed as glycosyl acceptors, although previous methods using a range of catalyst types have been developed in both inter- ${ }^{[16]}$ and intramolecular ${ }^{[17]}$ glycosylations. The reduced Lewis basicity of silyl ethers compared with free alcohols and the tunable nature of silyl ethers present unique opportunities in the development of catalytic glycosylation methodology.

Our recent work has developed the coupling of glycosyl fluorides and silyl ethers into a versatile method that accesses challenging glycosidic bonds while introducing preparative simplicity, robustness, and opportunities for iterative couplings. ${ }^{[11]}$ The use of $B\left(C_{6} F_{5}\right)_{3}$ as catalyst offers desirable characteristics including short reaction times, low catalyst loadings relative to the state of the art methods, ${ }^{[18]}$ and simple reaction conditions that are tolerant of moisture and air. Furthermore, the method enables access to each of the four possible C1-C2 stereochemical relationships through either inter- or intramolecular glycosylation, and iterative couplings can be achieved through the judicious choice of silyl protecting group to modulate the reactivity of competing hydroxyl nucleophiles. Notably, the iterative approach allows trisaccharides to be prepared in a site-selective, one-pot fashion from monosaccharide precursors (Scheme 1). A key aspect of the feasibility of the approach in the synthesis of more complex oligosaccharides is addressing the reversibility of glycoside bond formation. The suppression of glycoside scrambling is essential to the synthesis of oligosaccharides, whereas the promotion of glycoside scrambling may have important implications in chemical glycorandomization processes. ${ }^{[19]}$ The focus of this study is to evaluate the factors that enable or inhibit the glycosyl exchange under the conditions of boroncatalyzed glycosylation of glycosyl fluorides and silyl ethers and adds to a rich history of mechanism-based optimizations of the glycosylation reactions. ${ }^{[20]}$ 


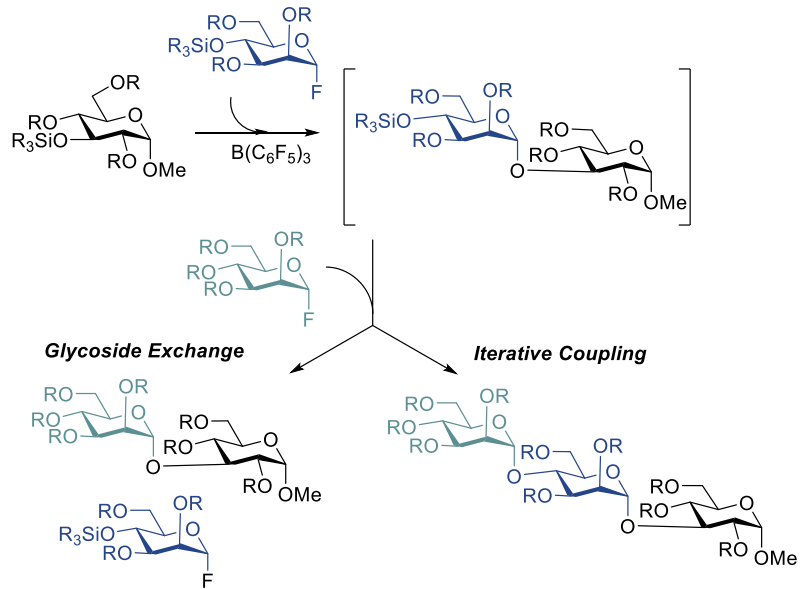

Scheme 1. Divergent outcomes observed herein.

\section{Results and Discussion}

A representative example of a three-component coupling plagued by competing glycosyl exchange is shown in (Scheme 2A), wherein glycosyl fluoride $\mathbf{1}$ first reacts with acceptor $\mathbf{2}$ to form the intermediate disaccharide 3. This then serves as an acceptor upon addition of glycosyl fluoride $\mathbf{4}$ resulting in the formation of trisaccharide 5. This reaction proceeds with excellent regiocontrol based on the size of silyl ether protecting group with the final trisaccharide retaining the TIPS group intact. To our surprise, we observed the unusual formation of disaccharide $\mathbf{6}$ in a similar yield to our desired trisaccharide product $\mathbf{5}$. When isolated disaccharide $\mathbf{3}$ was subjected to the reaction conditions to form trisaccharide 5 (Scheme 2B) the formation of disaccharide 6 was again observed, ruling out our initial hypothesis that this side product was being formed from unreacted $\mathbf{2}$. This observation led us to conclude that disaccharide $\mathbf{6}$ must result from the formal cleavage of the glycosidic bond in $\mathbf{3}$ followed by insertion of 4. A literature survey revealed little precedent for this kind of reactivity, with most methods for the chemical cleavage of glycosidic bonds occurring in protic solvents, in the presence of strong Brønsted acids, ${ }^{[21]}$ or promoted by Lewis acids using strong nucleophiles such as thiols. ${ }^{[22]}$ 


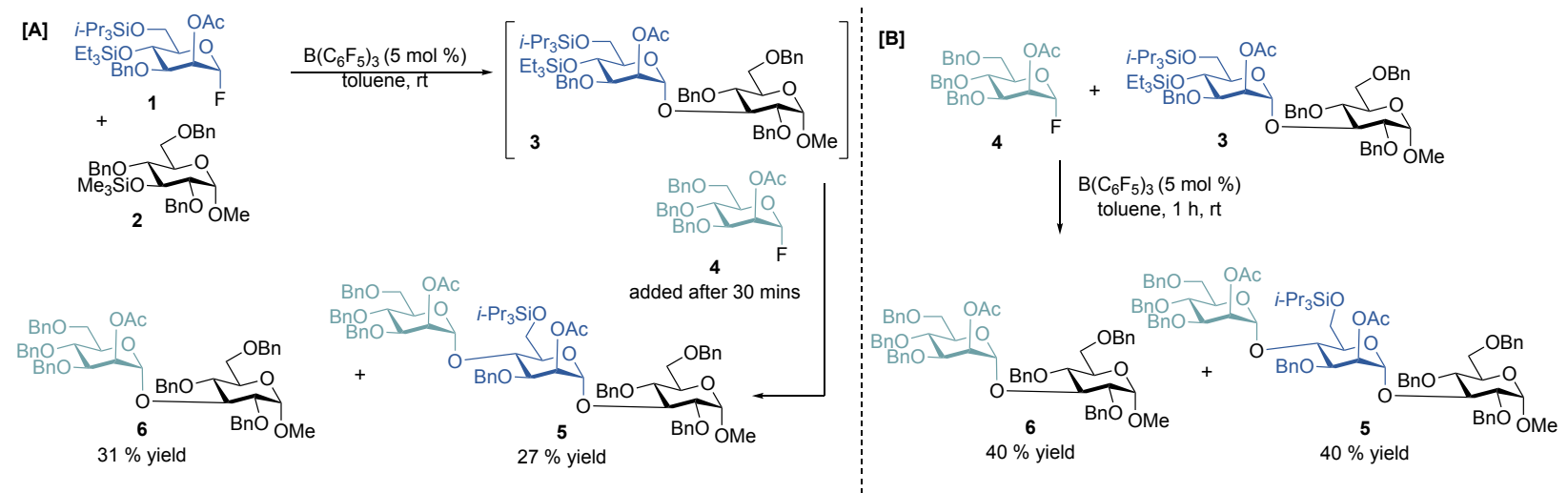

Scheme 2. (A) Initial observation of crossover in a three-component coupling. (B) Confirmation of the involvement of intermediate 3.

We considered three mechanistic hypotheses for the exchange process (Scheme 3). Our first hypothesis involved the formation of an electrophilic silyl species, which could coordinate to the glycosidic oxygen, promoting the formation of a dioxolenium ion as well as a new silyl ether linkage. A second possibility was that $B\left(C_{6} F_{5}\right)_{3}$ itself is a sufficiently strong Lewis acid to coordinate to the glycoside linkage and promote the scission of the glycosidic bond to form a dioxolenium ion with a boronate counterion. The glycosyl boronate formed by acetal cleavage through this pathway could then act as a glycosyl acceptor towards the glycosyl fluoride added last, resulting in the observed scrambled products. A third possibility is that $\mathrm{B}\left(\mathrm{C}_{6} \mathrm{~F}_{5}\right)_{3}$ and glycosyl fluoride 1 combine to form an oxocarbenium ion pair that can directly react with the glycosidic linkage in 6 resulting in the net exchange of dioxolenium ions. This final pathway is in direct analogy to the mechanism proposed by Li and Gildersleeve ${ }^{[23]}$ to explain the phenomenon of glycosyl exchange, commonly observed when employing thioglycoside acceptors.

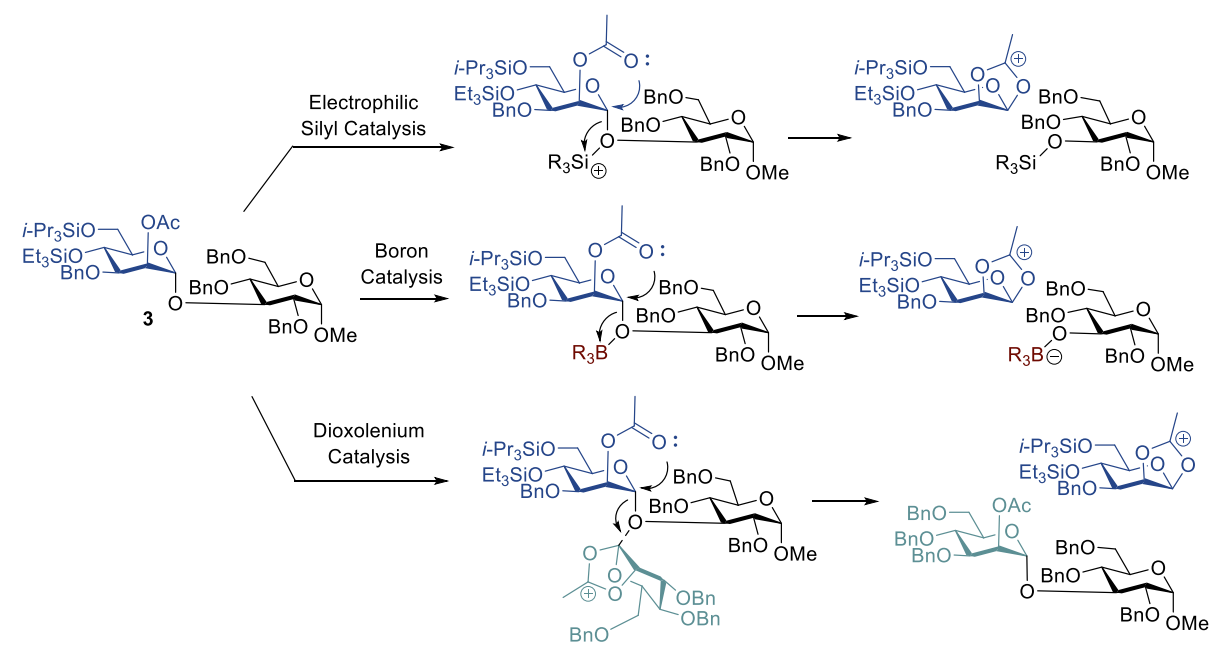


Scheme 3. Mechanistic possibilities considered for glycosyl exchange.

In our previous report on fluoride migration glycosylations, ${ }^{[11]}$ we employed methyl glycosides as acceptors in high-yielding glycosylations, under similar conditions employed herein, without observing glycosyl exchange. To explore this seeming inconsistency, we synthesized methyl glycoside acceptors with differing protecting groups and anomeric stereochemistry. Methyl glucoside acceptors that featured C-2 benzyl ethers $(\mathbf{7}, \mathbf{8})$ were the least susceptible to glycosyl exchange, with productive glycosylation completely outcompeting methyl glycoside exchange (Scheme 4A). However, acceptors that featured $\alpha$-mannosyl methyl glycosides $(\mathbf{1 1}, \mathbf{1 2})$ were more prone to glycosyl exchange. Methyl $\alpha$-mannoside acceptor featuring a C-2 benzyl ether $\mathbf{1 1}$ resulted in $3 \%$ crossover, whereas the analogous acceptor with a C-2 acetate $\mathbf{1 2}$ provided of the methyl $7 \%$ crossover product $\mathbf{1 5}$ (Scheme 4B). These simplified systems are useful for highlighting structural influences of acceptors, without the need for tedious multistep syntheses of disaccharide acceptors.

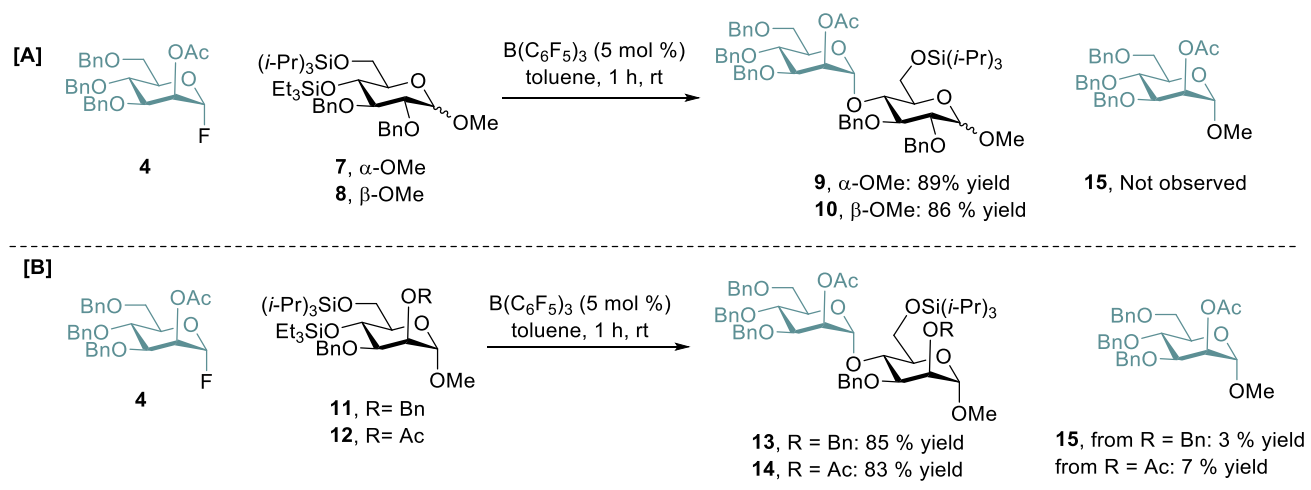

Scheme 4. (A) C-4 selective glycosylation of methyl glucosides. (B) C-4 selective glycosylation of methyl mannosides and isolated crossover products.

The size of the silyl ether acceptor additionally plays a dramatic role on the reaction outcome. Use of trimethyl silyl ether acceptor, 16 results in the clean formation of the desired trisaccharide $\mathbf{5}$ in $82 \%$ yield (Scheme 5), a dramatic improvement when compared to acceptor 3. 

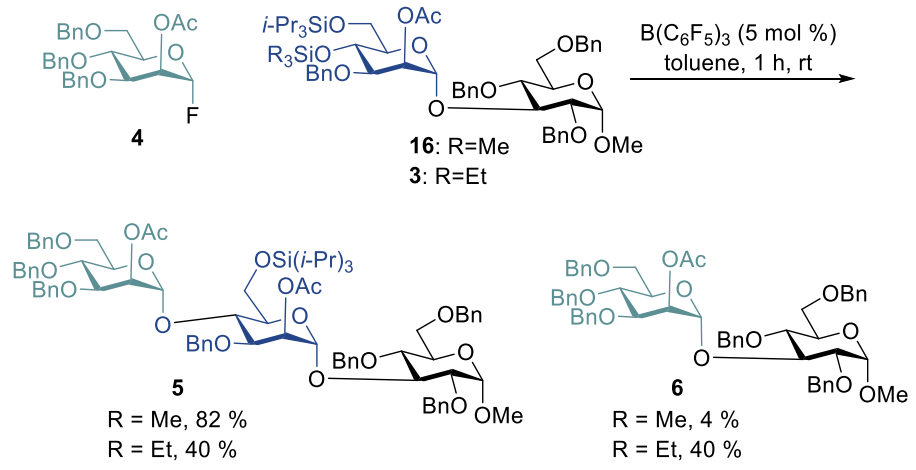

Scheme 5. Effect of silyl ether size.

$\mathrm{B}\left(\mathrm{C}_{6} \mathrm{~F}_{5}\right)_{3}$ is a strong Lewis acid and has been shown to promote carbocationic cascades and rearrangements. ${ }^{[24]}$ We evaluated the capabilities of this borane catalyst to reversibly promote the cleavage of glycosidic bonds. Glycosylation of $\mathbf{1 7}$ under standard $B\left(\mathrm{C}_{6} \mathrm{~F}_{5}\right)_{3}$ catalyzed conditions yielded the corresponding trisaccharide product 18 in $41 \%$ along with disaccharide 6 in $15 \%$ yield (Scheme 6A). This result confirmed that C2 esters are not required for this scrambling process, however, their absence appears to reduce the yield of the crossover product. When anomerically pure disaccharide 19 with an $\beta$-configuration, featuring a C-2 nonparticipating benzyl ether, was subjected to catalytic amounts of $B\left(\mathrm{C}_{6} \mathrm{~F}_{5}\right)_{3}$, no epimerization or consumption of the substrate was observed (Scheme 6B). Similarly, the $\alpha$-epimer of this disaccharide, $\mathbf{2 0}$ was also recovered unchanged from these same conditions (Scheme 7B). If the catalyst alone were reversibly activating this glycosidic bond, then we would expect to observe epimerization of this anomeric linkage towards its thermodynamic anomeric ratio (Scheme 6C). 
[A]
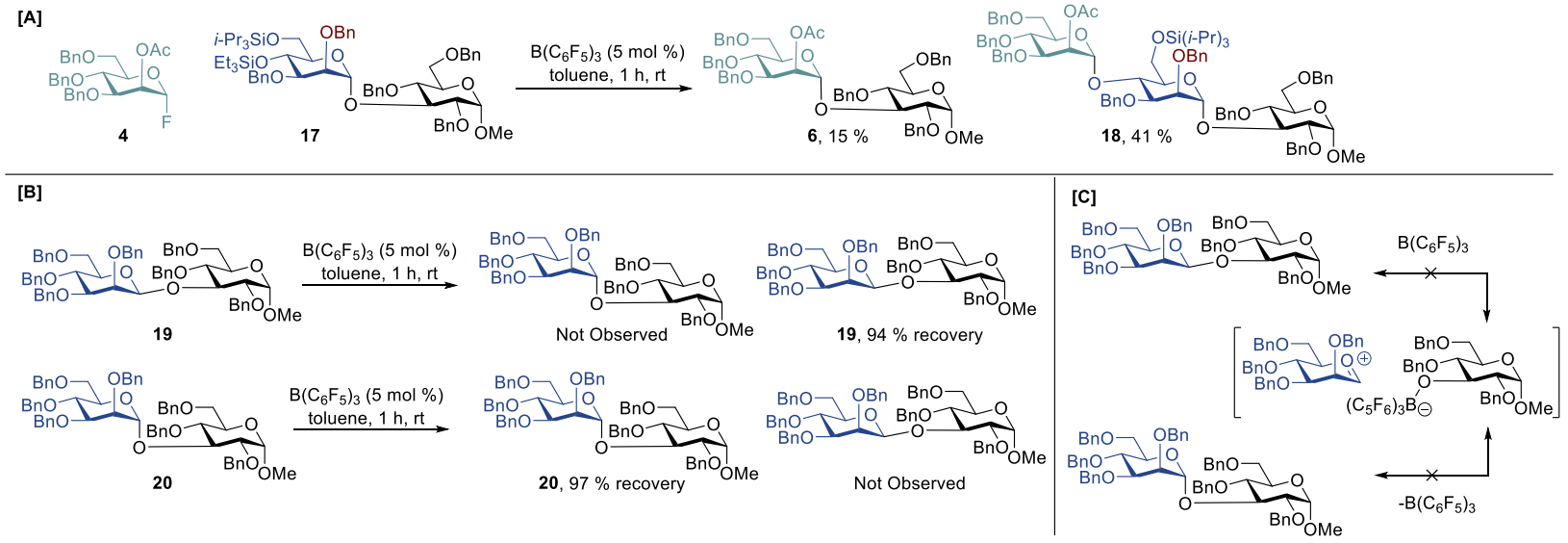

Scheme 6. (A) Substrates featuring C-2 nonparticipating groups subjected to glycosyl exchange conditions. (B)

Diastereomerically pure disaccharides subjected to $B\left(\mathrm{C}_{6} \mathrm{~F}_{5}\right)_{3}$. (C) Pathway for $\mathrm{B}\left(\mathrm{C}_{6} \mathrm{~F}_{5}\right)_{3}$ mediated diastereo-erosion of disaccharides.

There is extensive literature ${ }^{[24 a-c, 25]}$ precedent on the deoxygenation of ethers using silanes in the presence of catalytic $B\left(C_{6} F_{5}\right)_{3}$, that invoke the intermediacy of transient silylium species. We therefore postulated that there might be a possibility of $\mathrm{B}\left(\mathrm{C}_{6} \mathrm{~F}_{5}\right)_{3}$-mediated cleavage of silyl ether linkages or activation of the silyl fluoride product. This could allow access to an electropositive silicon species that could coordinate to the glycosidic bond and promote ionization to a dioxolenium and generation of a silyl ether. The newly formed silyl ether could then act as an acceptor for the formation of the glycosyl exchange product, consistent with our experimental observations. To eliminate any possibility of silyl cation-mediated glycosyl exchange, we designed an experiment that removed all the potential silyl sources from the reaction medium (Scheme 7A). We subjected disaccharide 6 and methyl ether protected mannosyl fluoride 21 to catalytic amount of $B\left(C_{6} F_{5}\right)_{3}$. After $16 \mathrm{~h}$, we recovered $42 \%$ of the initial disaccharide $\mathbf{6}$, as well as the crossover product $\mathbf{2 2}$ in $\mathbf{4 0} \%$ yield. This crossover experiment confirms that the exchange of one glycosidic linkage for another does not require a silylium source or a silyl ether. These findings can be replicated in the methyl glycoside series, activating both $\alpha$ (Figure 7B) and $\beta$ (see SI) diastereomers of 23. 

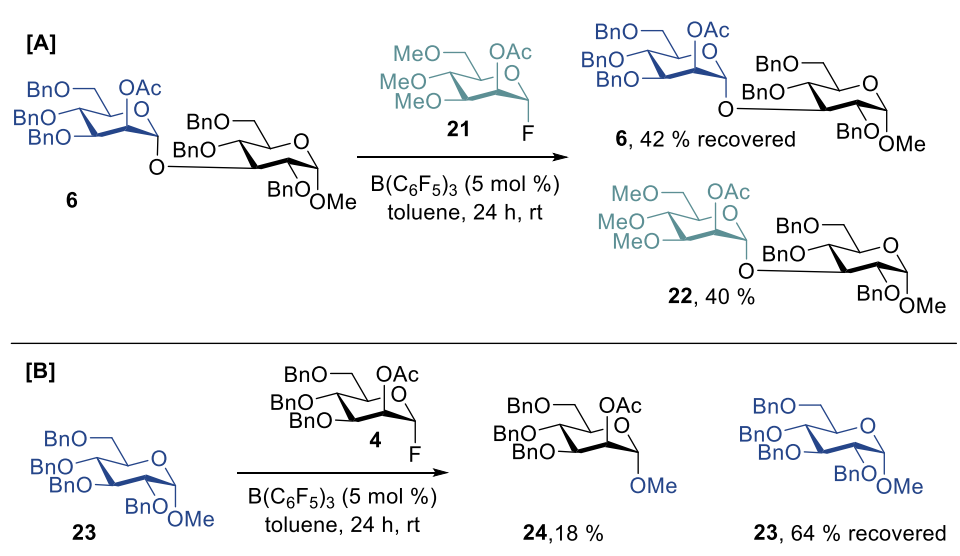

Scheme 7. (A) Methyl ether labeled crossover of a protected disaccharide. (B) Methyl glycoside exchange from glucose to mannose.

One open question about the reaction mechanism that remained was the fate of the excised sugar at the end of the reaction. We envisioned two competing possibilities: adventitious moisture, resulting in the formation of the hemiacetal and subsequently a complex mixture of uncharacterized byproducts. Alternatively, the fluoride from the donor could potentially be transferred, resulting in the formation of a new glycosyl fluoride. We attempted to engineer a model system such that the newly formed glycosyl fluoride would be stabilized and isolable after quenching the reaction. After disaccharide $\mathbf{2 5}$ was subjected to the reaction conditions, the $\alpha$ glucosyl fluoride $\mathbf{2 6}$ was isolated in $\mathbf{3 6} \%$ yield (Scheme 8). This product is sufficiently unreactive due to various stabilizing factors including the enhanced anomeric stabilization of $\alpha$-glucosyl fluorides ${ }^{[26]}$ as well as being cis to the C-2 participating group ${ }^{[27]}$ and therefore unable to undergo anchimeric assistance by the carbonyl oxygen. This experiment demonstrates that the isodesmic exchange of one glycosyl fluoride for another is viable under these reaction conditions.

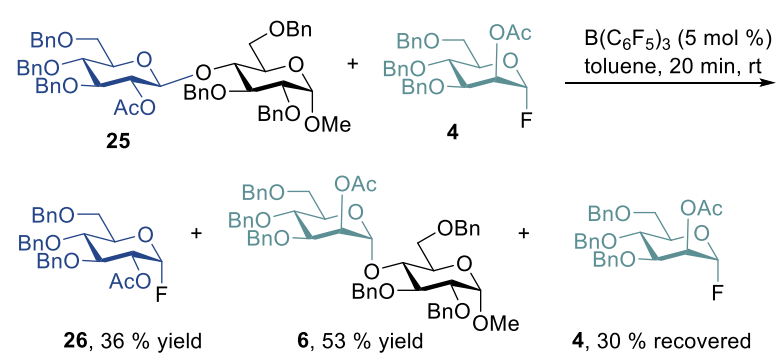

Scheme 8. Isolation of glycosyl fluoride crossover products. 
Based on the experimental observations that both a glycosyl fluoride source and the Lewis acid are required for glycosyl exchange, we propose that this process is mediated directly by the oxocarbenium/dioxolenium species that is generated in situ. The feasibility of this process was extensively evaluated using quantum mechanical simulations ${ }^{[28]}$ ( $\omega B 97 X-D 3 /(S M D$, Toluene)/def2-TZVP//B97-D/B1, see computational details in SI), employing a model featuring methyl ethers. We compared the reaction pathways for productive glycosylation with the glycosyl exchange process and found that both pathways were viable at room temperature. Relatively small differences in the energetic landscape are consistent with a reaction that provides close to a 1:1 distribution of products. Both pathways (Scheme 9) begin with the ionization of the glycosyl fluoride by $\mathrm{B}\left(\mathrm{C}_{6} \mathrm{~F}_{5}\right)_{3}$ to provide 28 , a dioxolenium ion pair, which is $4.2 \mathrm{kcal} / \mathrm{mol}$ uphill from 27 . The predicted exchange pathway proceeds via the interaction of this dioxolenium ion to the glycosidic ether through lone pair donation, providing 29. Next, a sterically congested oxonium species featuring three appended glycosides $\mathbf{3 0}$, is formed with a $13.1 \mathrm{kcal} / \mathrm{mol}$ barrier TS2. This oxonium then collapses to a stabilized dioxolenium ion $\mathbf{3 1}$ via TS3, which is the highest point on this reaction profile at $14.1 \mathrm{kcal} / \mathrm{mol}$. Dioxolenium 28 can alternatively enter a productive glycosylation pathway, through coordination with the Lewis basic silyl ether to provide 33 . The formation of a transient oxonium $\mathbf{3 4}$ via a nucleophilic attack of the silyl ether on the oxocarbenium with rupture of the five membered ring of $\mathbf{3 3}$ proceeds with an activation barrier of $13.0 \mathrm{kcal} / \mathrm{mol}$ TS4. Finally, facile delivery of the fluoride to the triethylsilyl ether results in the formation of trisaccharide $\mathbf{3 5 .}$ 


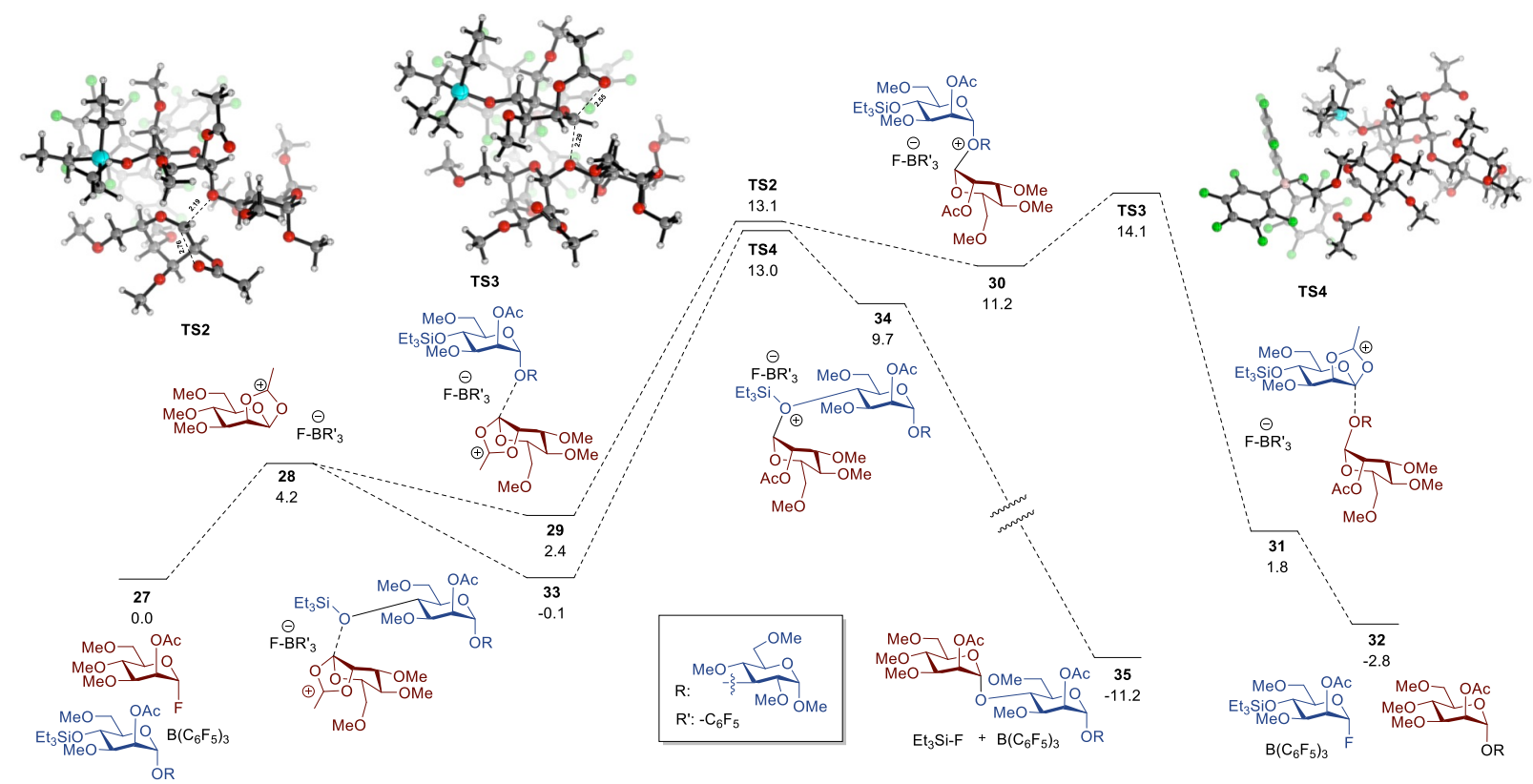

Scheme 9. Simulated energetic (Gibbs Free Energy) profile of divergent glycosylation outcomes using $\omega B$ B7X-

D3/(SMD, Toluene)/def2-TZVP//B97-D/B1. Energies are provided in kcal/mol.

\section{Catalyst design and structural effects}

Based on the reaction pathways in Scheme 9, we were interested in studying how the catalyst structure affects the relative rates of the two competing processes. We initiated our investigation by systematically preparing analogues of $\mathrm{B}\left(\mathrm{C}_{6} \mathrm{~F}_{5}\right)_{3}$, that feature fewer electronegative fluorine atoms, resulting in weaker Lewis acids ${ }^{[29]}$ and therefore, tighter bound anions. There is little change in reactivity from $B\left(C_{6} F_{5}\right)_{3}$ to $B\left(2,3,5,6-C_{6} F_{4} H\right)_{3}$, however, $\mathrm{B}\left(2,4,6-\mathrm{C}_{6} \mathrm{~F}_{3} \mathrm{H}_{2}\right)_{3}$ provides a significant increase in the yield of the glycosylation product 5 (67 \% yield) as well as an improved ratio of glycosylation to glycosyl exchange products (from 1:1 to $4: 1$ ). $B\left(\mathrm{C}_{6} \mathrm{~F}_{2} \mathrm{H}_{3}\right)_{3}$ also provides improved yields of 5; however, the reaction is very slow, requiring increased catalyst loading and a longer reaction time to proceed to completion, and is not preparatively useful for enabling efficient multi-component couplings. The ability of weaker Lewis acids to inhibit oxocarbenium scrambling suggests that the identity of the counterion in both pathways is crucial to the reaction outcome, with more weakly-coordinating anions promoting increased rates of side reactivity. 


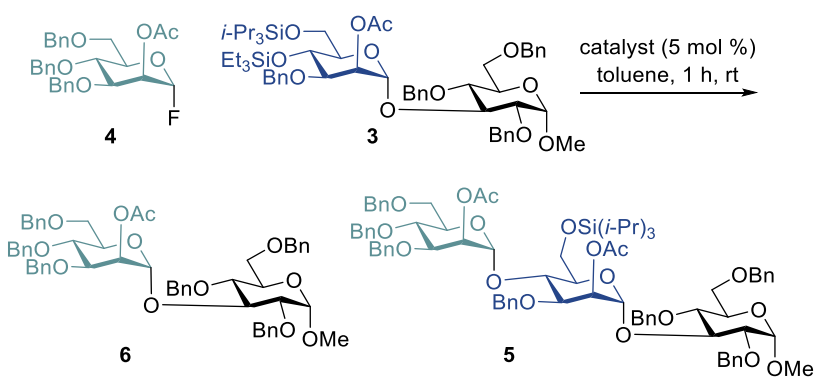

\begin{tabular}{cccc} 
Entry & Catalyst & Yield $\mathbf{6}(\%)$ & Yield $\mathbf{5}(\%)$ \\
\hline 1 & $\mathrm{~B}\left(\mathrm{C}_{6} \mathrm{~F}_{5}\right)_{3}$ & 40 & 40 \\
2 & $\mathrm{~B}\left(\mathrm{C}_{6} \mathrm{~F}_{4} \mathrm{H}\right)_{3}$ & 44 & 41 \\
3 & $\mathrm{~B}\left(\mathrm{C}_{6} \mathrm{~F}_{3} \mathrm{H}_{2}\right)_{3}{ }^{\mathrm{a}}$ & 16 & 67 \\
4 & $\mathrm{~B}\left(\mathrm{C}_{6} \mathrm{~F}_{2} \mathrm{H}_{3}\right)_{3}{ }^{\mathrm{b}}$ & 13 & 59 \\
5 & $\mathrm{~B}\left(\mathrm{C}_{6} \mathrm{~F}_{5}\right)_{\left(\mathrm{C}_{6} \mathrm{Cl}_{2} \mathrm{H}_{3}\right)^{\mathrm{a}}}$ & 33 & 45 \\
6 & $\mathrm{~B}\left(\mathrm{C}_{6} \mathrm{~F}_{5}\right)_{3} \cdot \mathrm{H}_{2} \mathrm{O}$ & 16 & 40 \\
7 & $\mathrm{~B}\left(\mathrm{C}_{6} \mathrm{~F}_{5}\right)_{3} \cdot \mathrm{Et}_{2} \mathrm{O}$ & 20 & 56 \\
8 & $\mathrm{BF}_{3} \cdot \mathrm{OEt}_{2}{ }^{\mathrm{c}}$ & 5 & 83 \\
9 & $\mathrm{BF}_{3} \cdot \mathrm{THF}^{\mathrm{d}}$ & 11 & 68
\end{tabular}

a $2 \mathrm{~h} .{ }^{\mathrm{b}} 10 \mathrm{~mol} \%$ and $5 \mathrm{~h}$ reaction time. ${ }^{\mathrm{c}} 25 \mathrm{~mol} \% \mathrm{~d} 3 \mathrm{~h}$

Table 1. Effects of catalyst structure.

$\mathrm{B}\left(\mathrm{C}_{6} \mathrm{~F}_{5}\right)_{3}$ and related boranes are known to form stable adducts with various Lewis bases. We studied the effect of Lewis basic additives in order to understand the degree of attenuation of Lewis acidity. Utilizing the preformed monohydrate of $\mathrm{B}\left(\mathrm{C}_{6} \mathrm{~F}_{5}\right)_{3},{ }^{[30]}$ we observed (Table 1, entry 6) a significant decrease in the yield of the glycosyl exchange product $\mathbf{6}$, with no corresponding increase in the production of the glycosylation product $\mathbf{5}$. The diminished mass balance is likely due to competing hydrolysis of various reactive intermediates. The diethyl ether adduct of $\mathrm{B}\left(\mathrm{C}_{6} \mathrm{~F}_{5}\right)_{3}$ provided a favorable reaction rate, an increased yield of trisaccharide 5 and improved selectivity (approximately 3:1) for direct glycosylation (Table 1, entry 7).

We then probed the role that steric environment of the Lewis acid and resulting counterion played in the selectivity of these reactions. There are various competing measures for Lewis acidity, ${ }^{[31]}$ many of which are sensitive to the steric environment around the acid and it is impossible to completely decouple Lewis acidity from 
steric size. We picked three Lewis acids of similar acidity that feature different steric profiles. Increasing the size of the Lewis acid, by introducing a 2,6-dichloro substitution pattern on one of the aryl substituents, did not dramatically change the reaction outcome (Table 1, entry 5). The minor improvements in the ratio of products when using $B\left(\mathrm{C}_{6} \mathrm{~F}_{5}\right)_{2}\left(\mathrm{C}_{6} \mathrm{Cl}_{2} \mathrm{H}_{3}\right)$ is also consistent with this borane being a weaker Lewis acid as compared to $\mathrm{B}\left(\mathrm{C}_{6} \mathrm{~F}_{5}\right)_{3} \cdot{ }^{[29 \mathrm{a}]} \mathrm{BF}_{3} \cdot \mathrm{OEt}_{2}$ is the most practical small borane of similar Lewis acidity, and when this is used as the catalyst, there is a marked changed in the reaction outcome (Table 1,entry 8), 5 was isolated in $83 \%$ yield, as compared to $5 \%$ of 6 . Use of $\mathrm{BF}_{3} \bullet \mathrm{THF}$ also provided similar results (Table 1 , entry 9 ), but with a diminished reaction rate, consistent with tetrahydrofuran being a more coordinating Lewis base than diethyl ether.

We reexamined the computed reaction pathways for the productive and crossover reactions utilizing $\mathrm{BF}_{3} \bullet \mathrm{OEt}_{2}$ and $\mathrm{B}\left(\mathrm{C}_{6} \mathrm{~F}_{5} \mathrm{H}_{2}\right)_{3}$. Consistent with literature findings ${ }^{[29]} \mathrm{B}\left(\mathrm{C}_{6} \mathrm{~F}_{5}\right)_{3}$, the strongest Lewis acid of this series, provided an ion pair that is endergonic by only $4.2 \mathrm{kcal} / \mathrm{mol}$, whereas $B\left(\mathrm{C}_{6} \mathrm{~F}_{3} \mathrm{H}_{2}\right)_{3}$ results in an ion pair that is energetically uphill from the reactants by $14.7 \mathrm{kcal} / \mathrm{mol}$. On the other hand, $\mathrm{BF}_{3} \bullet \mathrm{OEt}_{2}$ had to first lose the stable coordination provided by the Lewis basic diethyl ether before accessing the ion pair. Hence, in the $\mathrm{case}$ of $\mathrm{BF}_{3} \bullet \mathrm{OEt}_{2}$, the ion pair formation is significantly endergonic, $(20.7 \mathrm{kcal} / \mathrm{mol}$ above the starting fluoride and borane: Entry 3 , Table 2).

The considerably higher energetic cost towards ionization in the cases of $\mathrm{BF}_{3} \bullet \mathrm{OEt}_{2}$ and $\mathrm{B}\left(\mathrm{C}_{6} \mathrm{~F}_{3} \mathrm{H}_{2}\right)_{3} \mathrm{may}$ influence the selectivity between glycosylation and glycosyl exchange pathways, since the preferential stabilization of each pathway depends on the character of the Lewis acid. The overall reaction rate is thus influenced since $\mathrm{BF}_{3} \bullet \mathrm{OEt}_{2}$ requires a higher barrier to oxonium formation (see $\mathrm{SI}$ ) resulting in prohibitively kinetically slow glycosyl transfer. However, the iterative glycosylation pathway nonetheless remains kinetically accessible in case of $\mathrm{BF}_{3} \bullet \mathrm{OEt}_{2}$ and thereby produces the trisaccharide preferentially. 


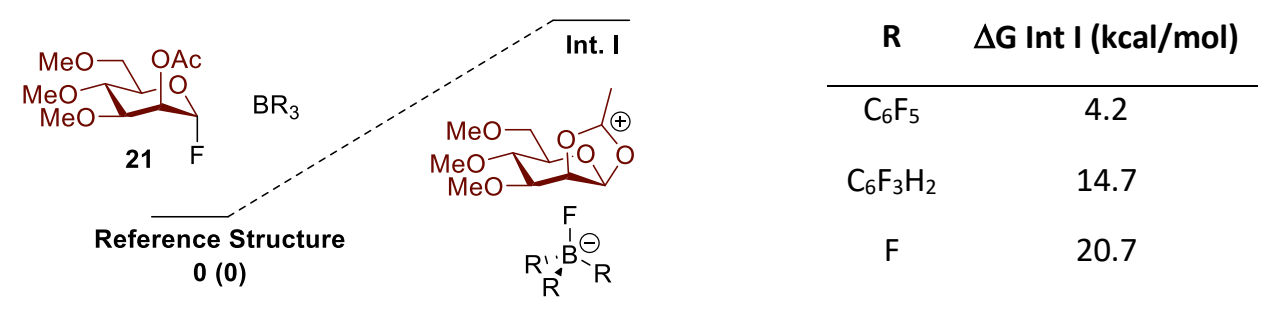

Table 2. Accessibility of ion pair for various Lewis acids.

Having systematically studied our model system, we then proceeded to extend these findings to one-pot, three-component couplings. The original conditions using $\mathrm{B}\left(\mathrm{C}_{6} \mathrm{~F}_{5}\right)_{3}$ resulted in $27 \%$ yield of the desired trisaccharide product 5 as well as $31 \%$ yield of disaccharide $\mathbf{6}$, whereas switching to the structurally related, but less Lewis acidic $\mathrm{B}\left(\mathrm{C}_{6} \mathrm{~F}_{3} \mathrm{H}_{2}\right)_{3}$ provided $58 \% 5$ as well as $19 \% \mathbf{6}$. Consistent with our findings in simplified systems, as well as our computational predictions, $\mathrm{BF}_{3} \bullet \mathrm{OEt}_{2}$ performed best out of all the catalysts screened, providing 5 in 61 $\%$ yield as well as the cleanest reaction profile (Scheme 10).

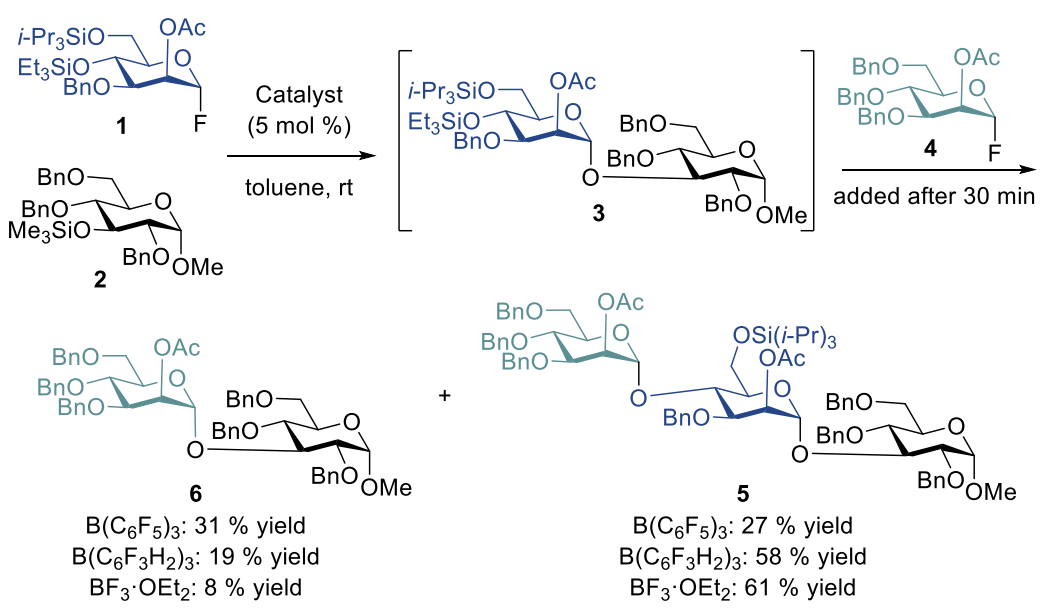

Scheme 10. Catalyst controlled suppression of glycosyl exchange.

Another benefit of using this catalytic system is its tolerance towards thioglycoside acceptors. $B\left(\mathrm{C}_{6} \mathrm{~F}_{5}\right)_{3}$ catalyzed coupling of $\mathbf{4}$ with $\mathbf{3 6}$ results in an approximately 1:1 mixture of thioether transfer product to the productive glycosylation, consistent with our mechanistic picture and in direct analogy to the findings of Gildersleeve. ${ }^{[23]}$ Moving to $\mathrm{BF}_{3} \bullet \mathrm{OEt}_{2}$ results in a dramatic improvement in the distribution of products, including a $56 \%$ isolated yield of $\mathbf{3 6}$. This result also translates to multicomponent couplings, where treating $\mathbf{3 9}$ with $\mathbf{4 0}$ in the 


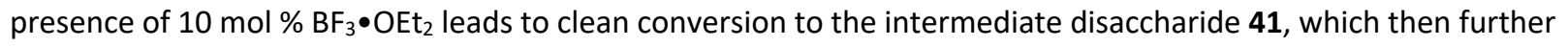
reacted in the presence of $\mathbf{4}$ to yield $\mathbf{4 2}$ in $\mathbf{4 5 \%}$ yield (see SI for details).
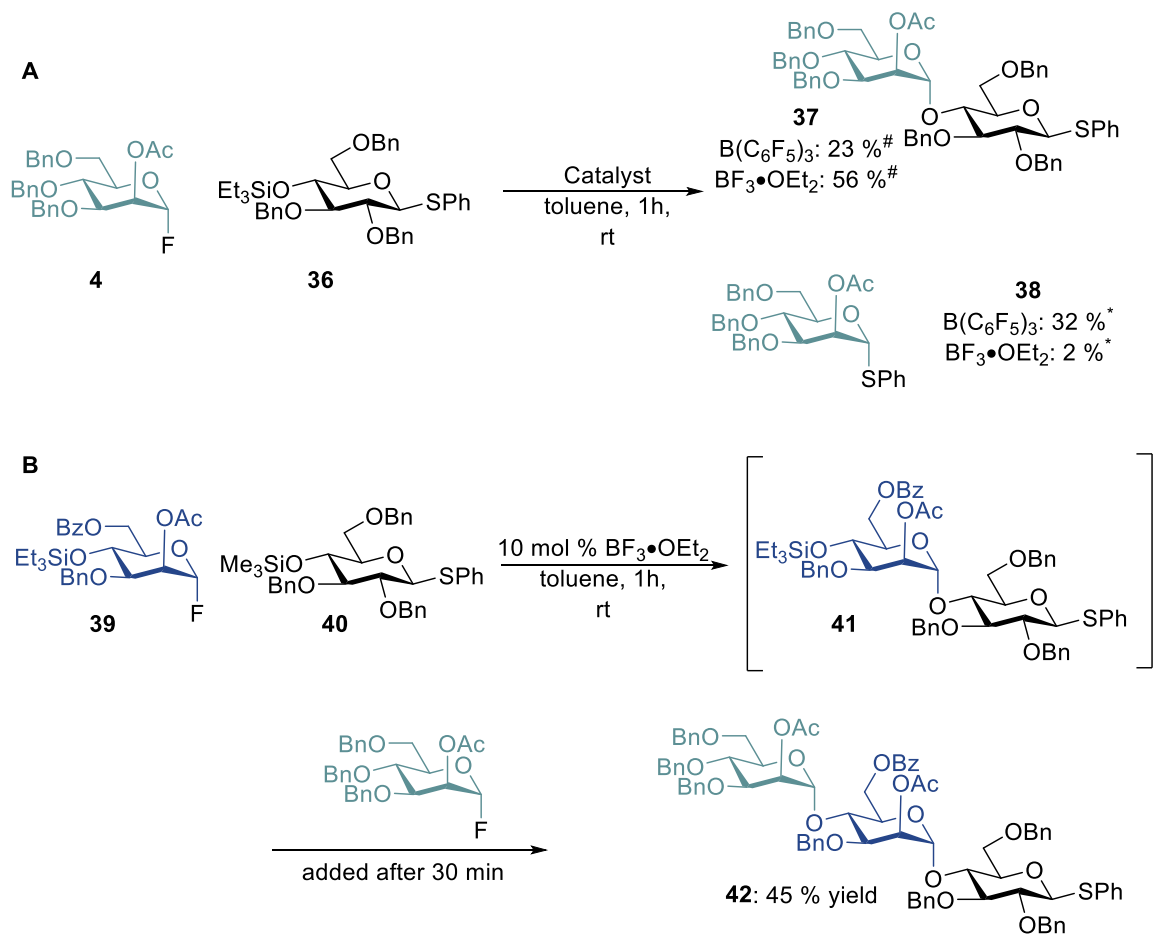

Scheme 11. (A) Effects of catalyst structure on two component glycosylation with thioglycoside acceptors. (B):

Extension to three component couplings. " Isolated, ${ }^{*}$ via ${ }^{1} \mathrm{H}$ NMR vs internal standard.

The opposite outcome can also be favored by employing fully protected disaccharides as substrates and $\mathrm{B}\left(\mathrm{C}_{6} \mathrm{~F}_{5}\right)_{3}$ as the catalyst. The glycosyl exchange of substrate $\mathbf{2 5}$ is particularly effective due to the enhanced stability of the resulting $\alpha$-glucosyl fluoride and employing a per-acetylated furanose donor (1 equiv.) allows for simplified purification of the resulting mixture due to the larger differences in polarity between starting materials and the glycosyl exchange product. Employing xylose fluoride $\mathbf{4 3}$ gave the corresponding disaccharide $\mathbf{4 5}$ in 49 \% yield, whereas the analogous reaction using ribose fluoride 44 provides disaccharide 46 in $55 \%$ yield. 


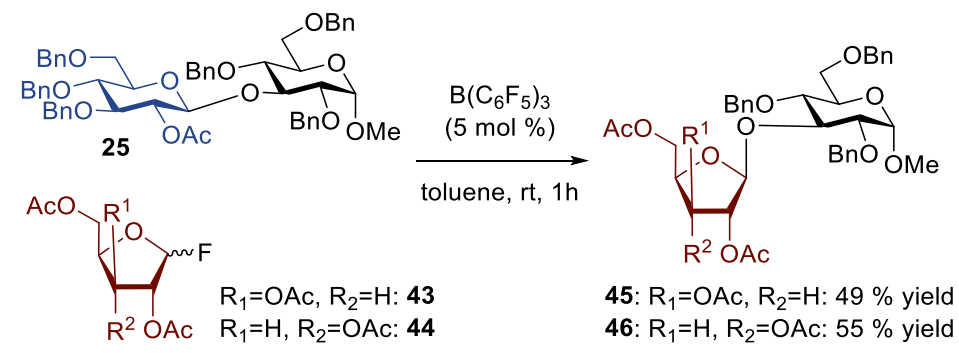

Scheme 12. Substrate enhanced glycosyl exchange utilizing equimolar quantities of disaccharide $\mathbf{2 5}$ and glycosyl fluorides 42-43.

\section{Conclusions}

Herein, we study an alternate reaction pathway for chemical glycosylations of sterically hindered or weak nucleophiles, involving the direct activation of glycosidic C-O bonds and their replacement with a different glycoside. Through a combined computational and experimental approach, we provide evidence that this process occurs via the direct insertion of a weakly coordinated dioxolenium into an existing glycosidic bond to provide a new glycosidic bond. This process is in a complex equilibrium and can be kinetically competitive with productive glycosylation ${ }^{[11]}$, especially when employing bulkier silyl protecting groups. More reactive Lewis acids such as $\mathrm{B}\left(\mathrm{C}_{6} \mathrm{~F}_{5}\right)_{3}$ lead to fast, productive, and selective reactions between glycosyl fluorides and trimethylsilyl ethers with little glycosyl exchange. With silyl groups larger than trimethylsilyl, as required in iterative approaches, the glycosyl exchange process becomes competitive and is promoted most effectively with $B\left(\mathrm{C}_{6} \mathrm{~F}_{5}\right)_{3}$. When the glycosyl exchange process is undesired, as with iterative couplings, weaker Lewis acids such $\mathrm{BF}_{3} \bullet \mathrm{OEt}_{2}$ are most effective at promoting glycoside bond formation while inhibiting glycoside exchange involving existing glycosidic linkages. This understanding allows conditions to be rationally tailored to allow for selective activation of glycosidic bonds when desired. Favoring direct glycosylations will improve the outcomes of complex multicomponent couplings of this nature, with the potential of dramatically simplifying the synthesis of linear and branched medium-sized oligosaccharides. Alternatively, favoring glycosyl exchange presents an intriguing approach towards the activation of seemingly inert bonds and offers a novel approach for the glycodiversification of natural products, which will be the subject of future work in our lab.

\section{Acknowledgements}


The authors thank the National Institutes of Health Common Fund Program in Glycoscience (U01GM125274).

J.L.M., G.C.S., and J.M. thank the National Institutes of Health (R35-GM118133) for support for this work. J.L.M.

acknowledges support from the National Institutes of Health through the CBI Training program (T32GM008597). T.

M and P. M. Z. acknowledges support from the National Institutes of Health (R35-GM128830).

\section{References}

[1] a) S. I. Elshahawi, K. A. Shaaban, M. K. Kharel, J. S. Thorson, Chem. Soc. Rev. 2015, 44, 7591-7697; b) C. R. Bertozzi, Kiessling, L. Laura, Science (New York, N.Y.) 2001, 291, 2357; c) L. L. Kiessling, Bioorganic \& Medicinal Chemistry 2018, 26, 5229-5238.

[2] R. A. Laine, Glycobiology 1994, 4, 759-767.

[3] a) A. Kobata, Glycoconj J 2000, 17, 443-464; b) G. Lauc, I. Rudan, H. Campbell, P. M. Rudd, Mol. BioSyst. 2010, 6, 329-335.

[4] a) L. R. Ruhaak, G. Xu, Q. Li, E. Goonatilleke, C. B. Lebrilla, Chem. Rev. 2018, 118, 7886-7930; b) M. Ly, F. E. Leach, T. N. Laremore, T. Toida, I. J. Amster, R. J. Linhardt, Nat Chem Biol 2011, 7, 827-833; c) L. S. Bailey, F. Huang, T. Gao, J. Zhao, K. B. Basso, Z. Guo, Anal. Chem. 2021, 93, 3154-3162; d) J. Hofmann, H. S. Hahm, P. H. Seeberger, K. Pagel, Nature 2015, 526, 241-244; e) J. Sastre Toraño, O. AizpuruaOlaizola, N. Wei, T. Li, L. Unione, G. Jiménez-Osés, F. Corzana, V. J. Somovilla, J. M. Falcon-Perez, G.-J. Boons, Chemistry - A European Journal 2021, 27, 2149-2154.

[5] a) E. Saxon, C. R. Bertozzi, Science (New York, N.Y.) 2000, 287, 2007; b) J. M. Baskin, J. A. Prescher, S. T. Laughlin, N. J. Agard, P. V. Chang, I. A. Miller, A. Lo, J. A. Codelli, C. R. Bertozzi, Proceedings of the National Academy of Sciences 2007, 104, 16793; c) J. Hirabayashi, M. Yamada, A. Kuno, H. Tateno, Chem. Soc. Rev. 2013, 42, 4443-4458; d) K.-L. Hsu, K. T. Pilobello, L. K. Mahal, Nat Chem Biol 2006, 2, 153-157.

[6] L.-X. Wang, B. G. Davis, Chem. Sci. 2013, 4, 3381-3394.

[7] https://commonfund.nih.gov/Glycoscience.

[8] G. Báti, J.-X. He, K. B. Pal, X.-W. Liu, Chem. Soc. Rev. 2019, 48, 4006-4018.

[9] a) W.-L. Leng, H. Yao, J.-X. He, X.-W. Liu, Accounts of Chemical Research 2018, 51, 628-639; b) S. M. Levi, E. N. Jacobsen*, in Organic Reactions, pp. 801-852.

[10] a) S. S. Kulkarni, C.-C. Wang, N. M. Sabbavarapu, A. R. Podilapu, P.-H. Liao, S.-C. Hung, Chem. Rev. 2018, 118, 8025-8104; b) C.-C. Wang, J.-C. Lee, S.-Y. Luo, S. S. Kulkarni, Y.-W. Huang, C.-C. Lee, K.-L. Chang, S.-C. Hung, Nature 2007, 446, 896; c) C.-C. Wang, S. S. Kulkarni, J.-C. Lee, S.-Y. Luo, S.-C. Hung, Nat. Protoc. 2008, 3, 97.

[11] G. C. Sati, J. L. Martin, Y. Xu, T. Malakar, P. M. Zimmerman, J. Montgomery, J. Am. Chem. Soc 2020.

[12] a) A. V. Demchenko, Handbook of Chemical Glycosylation: Advances in Stereoselectivity and Therapeutic Relevance., Wiley, Weinheim, 2008; b) K. Toshima, Carbohydr. Res. 2000, 327, 15-26; c) M. Yokoyama, Carbohydr. Res. 2000, 327, 5-14.

[13] M. Teruaki, M. Yoshiyuki, S. Shin-ichiro, Chem. Lett. 1981, 10, 431-432.

[14] K. C. Nicolaou, A. Chucholowski, R. E. Dolle, J. L. Randall, J. Chem. Soc., Chem. Commun. 1984, 11551156.

[15] A. A. Joseph, A. Pardo-Vargas, P. H. Seeberger, J. Am. Chem. Soc. 2020, 142, 8561-8564.

[16] a) G. Stork, G. Kim, J. Am. Chem. Soc. 1992, 114, 1087-1088; b) G. Stork, J. J. La Clair, J. Am. Chem. Soc. 1996, 118, 247-248; c) M. Bols, J. Chem. Soc., Chem. Commun. 1992, 913-914.

[17] a) W.-S. Kim, S. Hosono, H. Sasai, m. Shibasaki, Tetrahedron Lett. 1995, 36, 4443-4446; b) S. Hashimoto, M. Hayashi, R. Noyori, Tetrahedron Lett. 1984, 25, 1379-1382; c) T. Zhu, G.-J. Boons, Tetrahedron Letters 1998, 39, 2187-2190.

[18] M. M. Nielsen, C. M. Pedersen, Chem. Rev. 2018, 118, 8285-8358.

[19] a) X. Fu, C. Albermann, J. Jiang, J. Liao, C. Zhang, J. S. Thorson, Nat Biotechnol 2003, 21, 1467-1469; b) R. W. Gantt, P. Peltier-Pain, J. S. Thorson, Nat. Prod. Rep. 2011, 28, 1811-1853; c) B. R. Griffith, J. M. Langenhan, J. S. Thorson, Curr. Opin. Biotechnol. 2005, 16, 622-630; d) J. M. Langenhan, B. R. Griffith, J. S. Thorson, Journal of Natural Products 2005, 68, 1696-1711.

[20] a) H. M. Christensen, S. Oscarson, H. H. Jensen, Carbohydr. Res. 2015, 408, 51-95; b) S. van der Vorm, T. Hansen, J. M. A. van Hengst, H. S. Overkleeft, G. A. van der Marel, J. D. C. Codée, Chem. Soc. Rev. 2019, 48, 4688-4706.

[21] a) W. G. Overend, C. W. Rees, J. S. Sequeira, J. Chem. Soc. 1962, 3429-3440; b) H. H. Jensen, M. Bols, Org. Lett. 2003, 5, 3419-3421; c) M. N. Namchuk, J. D. McCarter, A. Becalski, T. Andrews, S. G. Withers, J. Am. Chem. Soc. 2000, 122, 1270-1277; d) Y. Ding, E. E. Swayze, S. A. Hofstadler, R. H. Griffey, 
Tetrahedron Letters 2000, 41, 4049-4052; e) N. J. Pawar, L. Wang, T. Higo, C. Bhattacharya, P. K. Kancharla, F. Zhang, K. Baryal, C.-X. Huo, J. Liu, R. J. Linhardt, X. Huang, L. C. Hsieh-Wilson, Angew. Chem. Int. Ed. 2019, 58, 18577-18583; f) J. E. Shively, H. E. Conrad, Biochemistry 1976, 15, 3932-3942; g) H. Chen, H. Yamase, K. Murakami, C.-w. Chang, L. Zhao, Z. Zhao, H.-w. Liu, Biochemistry 2002, 41, 91659183.

[22] B. Wu, J. Yang, Y. He, E. E. Swayze, Org. Lett. 2002, 4, 3455-3458.

[23] Z. Li, J. C. Gildersleeve, J. Am. Chem. Soc. 2006, 128, 11612-11619.

[24] a) T. A. Bender, J. A. Dabrowski, M. R. Gagné, ACS Catal. 2016, 6, 8399-8403; b) D. J. Parks, J. M. Blackwell, W. E. Piers, J. Org. Chem. 2000, 65, 3090-3098; c) J. M. Lowe, B. E. Bowers, Y. Seo, M. R. Gagné, Angew. Chem. Int. Ed. 2020, 59, 17297-17300; d) S. V. Kostjuk, S. Ouardad, F. Peruch, A. Deffieux, C. Absalon, J. E. Puskas, F. Ganachaud, Macromolecules 2011, 44, 1372-1384; e) S. Banerjee, K. Vanka, ACS Catal. 2018, 8, 6163-6176.

[25] a) Y. Seo, M. R. Gagné, ACS Catal. 2018, 8, 6993-6999; b) Y. Seo, M. R. Gagné, ACS Catal. 2018, 8, 8185; c) A. Y. Houghton, J. Hurmalainen, A. Mansikkamäki, W. E. Piers, H. M. Tuononen, Nature Chem. 2014, 6, 983-988.

[26] R. U. Lemieux, K. B. Hendriks, R. V. Stick, K. James, J. Am. Chem. Soc. 1975, 97, 4056-4062.

[27] a) D. Crich, M. Li, Org. Lett. 2007, 9, 4115-4118; b) M. Heuckendorff, C. M. Pedersen, M. Bols, Org. Lett. 2011, 13, 5956-5959.

[28] a) P. M. Zimmerman, J. Chem. Phys. 2013, 138, 184102; b) P. Zimmerman, J. Chem. Theory Comput. 2013, 9, 3043-3050; c) P. M. Zimmerman, J. Comput. Chem. 2015, 36, 601-611; d) I. M. Pendleton, M. H. Pérez-Temprano, M. S. Sanford, P. M. Zimmerman, J. Am. Chem. Soc. 2016, 138, 6049-6060.

[29] a) J. A. Nicasio, S. Steinberg, B. Inés, M. Alcarazo, Chemistry - A European Journal 2013, 19, 11016$11020 ;$ b) J. L. Carden, A. Dasgupta, R. L. Melen, Chem. Soc. Rev. 2020, 49, 1706-1725.

[30] C. Bergquist, B. M. Bridgewater, C. J. Harlan, J. R. Norton, R. A. Friesner, G. Parkin, J. Am. Chem. Soc. 2000, 122, 10581-10590.

[31] a) M. A. Beckett, G. C. Strickland, J. R. Holland, K. Sukumar Varma, Polymer 1996, 37, 4629-4631; b) R. F. Childs, D. L. Mulholland, A. Nixon, , Can. J. Chem. 1982, 60, 801-808; c) J. R. Gaffen, J. N. Bentley, L. C. Torres, C. Chu, T. Baumgartner, C. B. Caputo, Chem 2019, 5, 1567-1583.

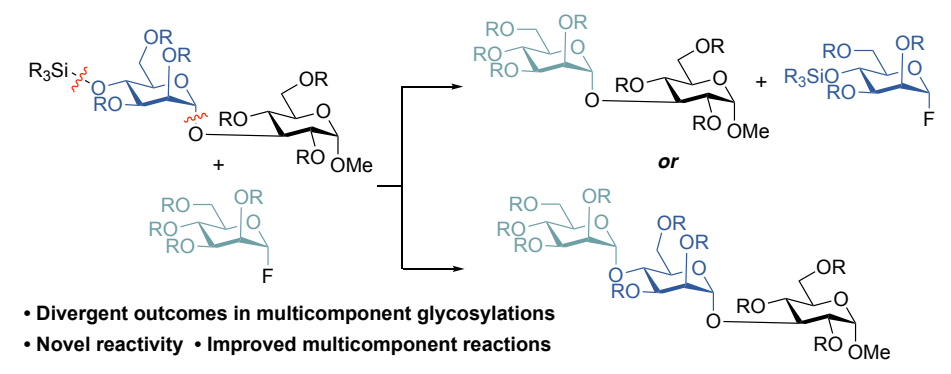

